\title{
Single-Step Selection of Mammalian Cell Mutants Deficient in CTP Synthetase
}

\author{
I-Chian Li, ${ }^{1}$ Chao-Liang Wu, ${ }^{1}$ and Ernest H.Y. Chu ${ }^{2}$ \\ ${ }^{1}$ Laboratory of Genetics, Department of Medicine, Medical College, National Cheng Kung University, Tainan, \\ Taiwan 70101; and ${ }^{2}$ Department of Human Genetics, University of Michigan Medical School, Ann Arbor, \\ Michigan 48109
}

Received 2 June 1988-Final 11 August 1988

\begin{abstract}
A single-step selection of Chinese hamster $V 79$ cells deficient in CTP synthetase $\left(C T P S^{-}\right)$is presented. The underlying principle of the direct selection is the differential and efficient killing of synchronized wild-type cells through incorporation of ${ }^{3} H /$ uridine and $\left[^{3} \mathrm{H}\right]$ thymidine. The CTPS ${ }^{-}$mutant cells were recovered by virtue of their not engaging in DNA synthesis, because (1) CTPS ${ }^{-}$cells are deficient in CTP synthetase and thus are unable to convert $\left[{ }^{3} \mathrm{H}\right] U T \mathrm{UP}$ into $\left[{ }^{3} \mathrm{H}\right] \mathrm{CTP}$, which eventually is converted into $\left.{ }^{3} \mathrm{H}\right] \mathrm{C} \mathrm{CTP}$ and incorporated into DNA; (2) the growth of CTPS ${ }^{-}$mutant cells was arrested as a result of cytidine deprivation, thus escaping the killing by the incorporation of $\left[{ }^{3} H\right]$ thymidine. The isolated mutant clones are auxotrophic for cytidine and are stable in phenotype with a reversion frequency of less than $1 \times 10^{-7}$. The mutant cells have no or very low CTP synthetase activity when tested by in vitro CTP synthetase assay or by whole-cell $\left.{ }^{3} H\right]$ uridine labeling assay. This modified "tritium suicide" method combined with the S-phase cell synchronization could provide a powerful means for the recovery from the cell population of nondividing mutant cells that are auxotrophic for some special nutrient requirement.
\end{abstract}

\section{INTRODUCTION}

CTP synthetase (UTP:L-glutamine ligase, EC 6.3.4.2) (abbreviated as CTPS) is a rate-limiting enzyme, catalyzing the irreversible conversion of UTP to CTP. CTP in the de novo pathway may be regarded as the starting material for the subsequent synthesis of other cytidine and deoxycytidine nucleotides, including CTP and dCTP, which are the precursors for the synthesis of RNA and DNA. CTPS is thus indispensable in rapidly proliferating cells.

CTPS is an allosteric enzyme; high concentration of CTP feedback inhibits CTPS (1). CTP feedback also inhibits aspartate transcarbamoylase and UDP reductase, thus reducing the rate of the de novo synthesis of UMP and the reduction rate of UDP to dUDP. This in turn decreases the intracellular pools of UTP and dTTP.

CTPS variants from different mammalian cell lines have been selected (2-7). All these variants show altered CTPS activity that is no longer sensitive to the negative regulation of CTP. As a consequence, these variants have expanded CTP and dCTP pools. This renders these cells auxotrophic for thymidine, resistant to the toxic effect of 1$\beta$-D-arabinofuranosyl-cytosine or 5-fluorouracil. More recently, Kelshall and Meuth (9) described the selection of CTP synthetase- 
deficient mutants of Chinese hamster ovary (CHO) cells. The selection was based on the reversion of a thymidine auxotrophic mutant (Thy-1) to prototroph with a concomitant change to CTP synthetase deficiency.

Deficiency of CTPS will make cell auxotrophic for cytidine. A low intracellular pool of CTP, and hence a low level of dCTP as well, is expected to disturb the highly regulated pyrimidine metabolism. It might also affect DNA synthesis by changing the ratio of dCTP to dTTP, since an appropriate ratio of dCTP to dTTP ensures the fidelity of DNA replication $(2,8,10)$. The availability of CTPSdeficient mutants in a cell culture system may allow experiments to elucidate the role of this enzyme in pyrimidine metabolism, and facilitate other studies such as the mapping of the human CTPS gene.

\section{MATERIALS AND METHODS}

Chemicals. $\left[5-{ }^{3} \mathrm{H}\right]$ Uridine $(28 \mathrm{Ci} /$ mmol) was purchased from Amersham Corporation (Buckinghamshire, England, United Kingdom). [ methyl $\left.-{ }^{3} \mathrm{H}\right]$ Thymidine was purchased from New England Nuclear (Boston, Massachusetts). $N$-(Phosphonacetyl)-L-aspartate (PALA) was obtained from Calbiochem (La Jolla, California). [5- $\left.{ }^{3} \mathrm{H}\right] \mathrm{UTP}$ was obtained from ICN Radiochemicals (Irvine, California). Ethyl methane sulfonate (EMS) was purchased from Sigma Chemical Company (St. Louis, Missouri).

Cells and Media. The cells used in this study were V79 Chinese hamster lung fibroblasts. The growth medium for all the experiments was Eagle's minimum essential medium (MEM with Earles' salt), supplemented with twofold of nonessential amino acids, 1.5fold of essential amino acids and vitamins, and 5\% fetal calf serum (FCS) (Gibco Lab., Grand Island, New York). In some experiments, dialyzed FCS was substituted for FCS to ensure that no exogenous nucleosides were present.
Isolation of Cytidine-Requiring Variants. Chinese hamster V79 cells were mutagenized with EMS (300 $\mu \mathrm{g} / \mathrm{ml})$ in MEM for 18 $\mathrm{h}$. The medium was removed, and a new medium was added that contained $5 \%$ dialyzed FCS, $1 \times 10^{-4} \mathrm{M}$ hypoxanthine, $1 \times$ $10^{-5} \mathrm{M}$ thymidine, $1 \times 10^{-6} \mathrm{M}$ aminopterin (HAT medium), $1 \times 10^{-4}$ M PALA, $1 \times 10^{-4}$ $\mathrm{M}$ uridine, and $1 \times 10^{-4} \mathrm{M}$ cytidine. Five days later, the cells were dispersed at a density of $10^{6}$ cells per $9-\mathrm{cm}$ culture dish in a growth medium supplemented with $5 \%$ dialyzed FCS and $1 \times 10^{-4} \mathrm{M}$ cytidine, but deficient in the essential amino acid methionine. Twenty-four hours later, a second cell synchronization step was introduced by changing the cells to a new medium containing 5\% FCS and $2 \mathrm{mM}$ hydroxyurea, but without cytidine. Ten hours later, the medium was removed and a new medium containing $\left[5-{ }^{3} \mathrm{H}\right]$ uridine $(1 \mu \mathrm{Ci} / \mathrm{ml})$ was added; the medium still did not contain any cytidine. After an 8-h exposure to the radioactive chemicals, the medium was removed, the dish was washed twice with phosphate-buffered saline (PBS), and a new medium containing $1 \times 10^{-4} \mathrm{M}$ cytidine was added. This medium was renewed the next day. Cell colonies that appeared after approximately four to five weeks were cloned and tested for their dependence on cytidine.

Measurement of Colony-Forming Ability in Various Media. To determine the ability of cells to form colonies in different media, 200 cells were seeded in quadruplicate into 60-mm culture dishes. After 7-10 days, the dishes were stained, and colonies were counted.

Whole-Cell $\left[{ }^{3} H\right]$ Uridine-Labeling Assay. Wild-type V79 and putative mutant cells, each at $2 \times 10^{6}$ cells per 60 -mm culture dish, were labeled with $5 \mu \mathrm{Ci}$ of $\left[5-{ }^{3} \mathrm{H}\right]$ uridine per milliliter of growth medium for $5 \mathrm{~h}$. The cells were then collected by trypsinization, sonicated, and heated to denature the macromolecules. After centrifugation, the supernatant containing nucleotides was treated for $5 \mathrm{hr}$ with alkaline phosphatase and phosphodies- 
terase, which convert nucleotides to nucleosides. The enzyme reaction was terminated by heating for $1 \mathrm{~min}$ in a $100^{\circ} \mathrm{C}$ water bath. It was followed by centrifugation to obtain clear supernatant, which contained nucleosides. Thin-layer chromatography was performed by spotting $10 \mu \mathrm{l}$ nucleoside solution on cellulose F sheet (Merck Company, West Germany) and developed in a solvent solution containing isopropanol, concentrated $\mathrm{HCl}$, and water. The spots corresponding to uridine and cytidine were cut out and the radioactivity was counted.

CPT Synthetase Assay. The assay was performed using a modified procedure of McLaren and Chu (11). Exponentially growing cells were harvested by trypsinization and washed with PBS by centrifugation. The cells were resuspended at $1 \times 10^{8}$ cells $/ \mathrm{ml}$ in 30 $\mathrm{mM}$ Tris $\mathrm{HCl}, \mathrm{pH} 7.5$, plus $50 \mathrm{mM}$ L-glutamine and $50 \mathrm{mM} \beta$-mercaptoethanol, and disrupted by Ystral homogenizer (Ystral, West Germany). After centrifugation at $100,000 \mathrm{~g}$ for $60 \mathrm{~min}$, the supernatant was either used immediately or frozen in aliquots at $-70^{\circ} \mathrm{C}$.

The reaction mixture in a volume of 25- $\mu$ l contained $100 \mathrm{mM}$ Tris $\mathrm{HCl}, \mathrm{pH} 7.5,8$ mM ATP, $0.2 \mathrm{mM}$ GTP, $0.2 \mathrm{mM}$ UTP, 25 $\mathrm{mM} \beta$-mercaptoethanol, $24 \mathrm{mM} \mathrm{MgCl}_{2}, 1$ mM EDTA, $10 \mathrm{mM} \mathrm{NaF}, 48 \mathrm{mM}$ L-glutamine, and $0.2 \mathrm{mM}\left[{ }^{3} \mathrm{H}\right] \mathrm{UTP}(1 \mu \mathrm{Ci})$. After incubation at $37^{\circ} \mathrm{C}$ for $60 \mathrm{~min}, 5 \mu \mathrm{l}$ of the reaction mixture was withdrawn and spotted immediately on polyethyleneimine-cellulose (PEI-cellulose) sheet (Merck). The sheet was then developed in $0.45 \mathrm{~N} \mathrm{HCl}$, and the spots corresponding to CTP and UTP were cut off and the radioactivity was counted.

\section{RESULTS}

Isolation of Cytidine-Requiring $\mathrm{Mu}$ tants. Figure 1 may help to elucidate the principle underlying our selection of cytidinerequiring mutants. Tritium-labeled uridine transported into the cells is first phosphory-

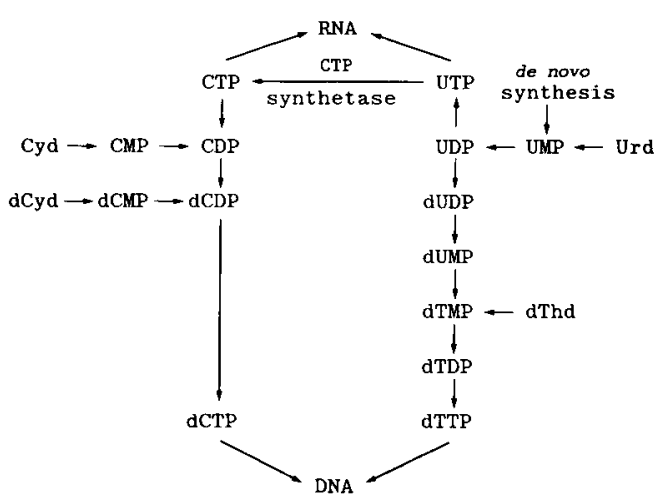

Fig. 1. Pyrimidine metabolism.

lated by uridine kinase into UMP, which is then converted into UDP and UTP. Via the action of CTPS, $\left[{ }^{3} \mathrm{H}\right]$ UTP is converted into $\left[{ }^{3} \mathrm{H}\right] \mathrm{CTP}$, which later follows the path of deoxycytidine metabolism and converted into $\left[{ }^{3} \mathrm{H}\right] \mathrm{dCTP}$ which is then incorporated into DNA. Thus, when cultured with $\left[{ }^{3} \mathrm{H}\right]$ uridine, the cells that incorporate tritium into DNA will die, whereas the cells that have defects in the pathways of uridine and cytidine will survive. The defects may involve mainly three enzymes, i.e., uridine kinase, UDP reductase, or CTPS. To avoid the selection of uridine kinase-deficient mutant, we first grew V79 cells in medium containing $1 \times 10^{-4} \mathrm{M}$ uridine and $1 \times 10^{-4} \mathrm{M}$ PALA. PALA is a strong inhibitor of aspartate transcarbamoylase (12) and thus blocks the de novo synthesis of UMP. In the presence of PALA and uridine, only those cells with intact uridine kinase activity can survive. However, following multiround exposures of V79 cells to $\left[5-{ }^{3} \mathrm{H}\right]$ uridine, we did not obtain any surviving colonies that were cytidine auxotrophs. We reasoned that it could be the result of the large amount incorporation of $\left[{ }^{3} \mathrm{H}\right] \mathrm{UTP}$ into RNA or to the long pathway of $\left[{ }^{3} \mathrm{H}\right]$ uridine to $\left[{ }^{3} \mathrm{H}\right] \mathrm{dCTP}$ to DNA. We thus devised a short labeling scheme. Accordingly, V79 cells were mutagenized with EMS. During the five days of mutation expression period, the medium contained uridine, PALA, cytidine, and HAT. The HAT medium was used to kill those cells 
deficient in thymidine kinase. The cells were then synchronized twice, once by methionine starvation and then by hydroxyurea treatment. Hydroxyurea blocks the cell population at the border of $G_{1}$ and $S$ phases of the cell cycle (13). During the 10-h treatment with hydroxyurea, the cells were also deprived of cytidine. The cells were allowed to enter DNA synthesis phase by medium change; the medium contained $\left[{ }^{3} \mathrm{H}\right]$ uridine and $\left[{ }^{3} \mathrm{H}\right]$ thymidine, but still without cytidine. Eight hours later the medium was removed, and the culture dishes were washed twice with PBS, and a new medium containing $1 \times 10^{-4} \mathrm{M}$ of cytidine and $1 \times 10^{-6} \mathrm{M}$ of thymidine was added. The medium containing cytidine was changed the next day. In two separate experiments using EMS as the mutagenic agent, we isolated three clones that were cytidine auxotrophs. The average frequency of occurrence was $1.8 \times 10^{-7}$. We did not find any spontaneous cytidine auxotrophs from three experiments using no mutagen.

Growth Characteristics of CytidineDependent Mutant. The cytidine-requiring phenotype in the three clones, CTPS-1, CTPS-2, and CTPS-3, was stable on culture for more than 13 months. The clones are totally dependent on cytidine; neither uridine, thymidine, nor deoxycytidine could support cell growth (Table 1). The plating efficiency of the mutants in $1 \times 10^{-4} \mathrm{M}$ cytidine was $100 \%$, they also grew well in $1 \times 10^{-3} \mathrm{M}$ cytidine, whereas V79 wild-type cells grew poorly in $1 \times 10^{-3} \mathrm{M}$ cytidine. This characteristic eliminates any revertant cells arising in the mutant cell population. No cell survived to form a colony from up to $10^{7}$ viable mutant cells that were plated in medium deficient in cytidine. The reversion frequency was, therefore, less than $1 \times 10^{-7}$. Since the de novo synthesis of cytidine nucleotides is via CTPS, and since there is no other pathway except the salvage pathway by which cytidine is phosphorylated, these results suggest that the mutant isolates must have defect in CTP synthesis.
Initially all the three mutant clones grew slowly. At the very beginning we had to wait for up to one month for the isolation of variant clones. Once they were isolated and gradually adapted to the growth medium containing $1 \times$ $10^{-3} \mathrm{M}$ or $1 \times 10^{-4} \mathrm{M}$ cytidine, the growth rates increased. CTPS- 1 cells have an average generation time of approximately $20 \mathrm{~h}$ as compared to the $16 \mathrm{~h}$ for the wild-type cells.

Karyotype analysis of the selected CTPS $^{-}$mutants showed that a modal chromosome number was 20 , which is the same as in the wild-type cell line.

CTP Synthetase Activity. The growth characters suggest that the cytidine-requiring phenotypes appear to be due to the loss of CTPS activity. This is verified by the CTPS assay using crude cell extract. No CTPS activity was detected in all three variant cell lines, while the wild-type cells were found to exhibit normal CTPS activity (an average of $4.8 \mathrm{nmol}$ CTP formed $/ \mathrm{mg}$ protein $/ \mathrm{h}$ ). This is further confirmed by a whole-cell $\left[{ }^{3} \mathrm{H}\right]$ uridine-labeling assay (see Materials and Methods). Radioactivity from the mutant cell line (CTPS-1) was found only in the uridine cutoff but not in the cytidine cutoff, while the wildtype cells exhibit radioactivity in both nucleoside spots (Table 2). The result indicates that CTPS-1 cells have very low CTPS activity in vivo to convert uridine nucleotides into cytidine nucleotides.

\section{DISCUSSION}

The "tritium suicide" method has been used successfully for the selection of mutants that are unable to incorporate ${ }^{3} \mathrm{H}$-labeled compounds into DNA. For instance, Urlaub and Chasin (14) used $\left[{ }^{3} \mathrm{H}\right]$ deoxyuridine as the selective agent to select for Chinese hamster cell mutants deficient in dihydrofolate reductase activity. Ayasawa et al. (15) also used $\left[{ }^{3} \mathbf{H}\right]$ deoxyuridine to select for mouse FM3A cell mutants defective in thymidylate synthetase. However, in those cases, multiround exposures of cells to the radioactive chemicals 


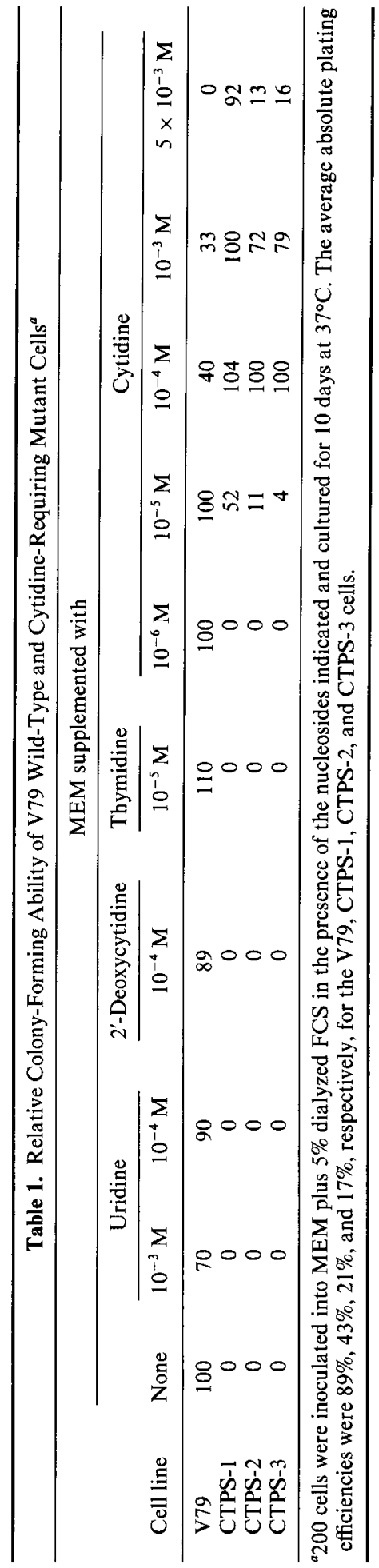


Table 2. Whole-Cell $\left[{ }^{3} \mathrm{H}\right]$ Uridine-Labeling Assay of V79 Wild-Type and CTPS-1 Mutant Cells ${ }^{a}$

\begin{tabular}{lcc}
\hline & \multicolumn{2}{c}{ Radioactivity (\%) } \\
\cline { 2 - 3 } Cell line & Cytidine & Uridine \\
\hline V79 & 8.55 & 86.90 \\
CTPS-1 & 0.40 & 97.53 \\
\hline
\end{tabular}

${ }^{a}$ See Materials and Methods for details of the experiment.

were needed. Furthermore, in addition to the desired mutant cells, a lot of kinase-deficient mutants unable to phosphorylate the radioactive compounds were found, making the selection inefficient.

In the present selection scheme, three considerations are deemed crucial to its success. In the first place, we incorporated two selective formulations to kill cells deficient in either uridine kinase or thymidine kinase from the mutagenized cell population, thus avoiding the recovery of undesired mutants. Second, we combined the tritium suicide method with the cell synchronization at the $S$ phase to facilitate the incorporation of radioactive precursors for DNA synthesis and to selectively eliminate wild-type cells in one strike. In this manner, we avoided the laborious cycles of cell labeling and growing the surviving cells. Those cells survived mainly because they were not in the $S$ phase of the cell cycle and hence were not killed by the tritium. Third, by depriving the mutant CTPS $^{-}$cells of the needed cytidine, the growth and the DNA synthesis of these cells were arrested temporarily. The putative mutants can then be rescued upon the addition of cytidine.

In mammals, the location of the genetic locus specifying CTPS (ctps) is unknown. If the gene is autosomal, in order to obtain a homozygous recessive mutant with a complete enzyme deficiency, a double hit by mutagen is usually necessary. The frequency may be as low as $1 \times 10^{-7}(14,16)$. In our case, the V79 cell population did not spontaneously give rise to a mutant lacking CTPS activity. The frequency of occurrence of $\mathrm{CTPS}^{-}$mutant in
EMS-induced cell population was also very low. These facts suggest that there might be at least two wild-type alleles for the ctps locus in this pseudodiploid cell line (17).

In view of the rate-limiting nature of CTPS, one might expect that a deficiency of CTPS would have a profound effect on the highly regulated pyrimidine metabolism. That this seems to be the case is shown at least by the slow-growing nature of the three selected CTPS ${ }^{-}$mutants. Moreover, in a preliminary experiment, we found that CTPS-1 cells in the absence of cytidine are more sensitive to UV light as compared to the wild-type cells. A CTPS-deficient mutant, together with a CTPS-amplified mutant, which we have isolated several clones, should be of great value in investigating the mechanism of CTP regulating the pyrimidine metabolism. The mutants should also provide a system for the study of molecular somatic genetics. Using a CTPS mutant line and a normal human lymphoblastoid line, we have obtained hybrid clones that are cytidine prototrophs. We are now in the process of mapping the human gene coding CTPS.

\section{ACKNOWLEDGMENTS}

We thank Dr. Kun-yen Huang and Miss Willisa Liou for reading the manuscript. We are indebted to Miss Ya-Jane Chen for technical assistance. The work was supported by grants NSC 76-0412-B006-21 and NSC 770412-B006-21 from the National Science Council, Taiwan; and GM 20608 from the U.S. Public Health Service.

\section{LITERATURE CITED}

1. Wright, J.A. (1983). Pharmacol. Ther. 22:81-102.

2. Chu, E.H.Y., McLaren, J.D., Li, I.C., and Lamb, B. (1984). Biochem. Genet. 22:701-715.

3. McLaren, J.D., and Chu, E.H.Y. (1984), Biochem. Genet. 22:717-727.

4. de Saint Vincent, B.R., and Buttin, G. (1980). Biochim. Biophys. Acta 610:352-359.

5. Trudel, M., Van Genechten, T., and Meuth, M. (1984). J. Biol. Chem. 259:2355-2559. 
6. Kaufman, E.R. (1984). Cancer Res. 4:3371-3376.

7. Arrow, B., Watts, T., Lassetter, J., Washtien, W., and Ullman, B. (1984). J. Biol. Chem. 259:90359043.

8. Meuth, M., L'-Heureux-Huard, N., and Trudel, M. (1979). Proc. Natl. Acad. Sci. U.S.A. 76:65056509.

9. Kelshall, A., and Meuth, M. (1988). Somat. Cell Mol. Genet. 14:149-154.

10. Weinberg, G., Ullman, B., and Martin, D.W., Jr. (1981). Proc. Natl. Acad. Sci. U.S.A. 78:24472451 .
11. McLaren, J.D., and Chu, E.H.Y. (1983). Mol. Cell. Biochem. 57:167-175.

12. Swyryd, E.A., Seaver, S.S., and Stark, G.R. (1974). J. Biol. Chem. 249:6945-6950.

13. Wawra, E., and Wintersberger, E. (1983). Mol. Cell Biol. 3:297-304.

14. Urlaub, G., and Chasin, L.A. (1980). Proc. Natl. Acad. Sci. U.S.A. 77:4216-4220.

15. Ayusawa, D., Koyama, H., Iwata, K., and Seno, T. (1980). Somat. Cell Mol. Genet. 6:261-270.

16. Chasin, L.A. (1974). Cell 2:37-41.

17. Siminovitch, L. (1967). Cell 7:1-12. 